\title{
Znaczenie spawalnictwa w procesie remanufacturingu
}

\author{
The role of welding engineering \\ in the remanufacturing
}

\section{Streszczenie}

W artykule przedstawiono charakterystykę procesu remanufacturingu oraz uwarunkowania ekonomiczne i techniczne stosowania tych metod przywracania części do użytkowania. Omówiono również zastosowanie metod spawalniczych do wykonywania powłok o charakterze naprawczym.
Abstract

The article presents the characteristics of the remanufacturing process, economic conditions and technical application of these methods of regeneration parts for use. It presents also the use of welding methods for repair coatings.

\section{Wstęp}

Spawalnictwo jest jedną z podstawowych metod wytwarzania. Różnorodne konstrukcje spajane znajdują zastosowanie w każdej dziedzinie życia, począwszy od części elektronicznych o mikrometrycznych rozmiarach, aż do wielkogabarytowych konstrukcji lądowych. Metody spajania, oprócz łączenia materiałów technicznych znajdują również inne zastosowanie np. podczas modyfikacji oraz regeneracji powierzchni różnorodnych części maszyn. W obecnej sytuacji gospodarczo-ekonomicznej, w świetle stale rosnących kosztów wytwarzania oraz drożejących materiałów konstrukcyjnych stosowanych do budowy specjalistycznych maszyn i urządzeń, można zauważyć wyraźne zainteresowanie przemysłu odtwarzaniem właściwości użytkowych drogich części maszyn. Odtwarzanie właściwości eksploatacyjnych części maszyn stało się już właściwie nową ważną gałęzią przemysłu, a zakresem działania sięga od prostych napraw aż po złożone technologicznie i proceduralnie procesy remanufacturingu.

W remanufacturingu stosuje się wiele metod modyfikacji powierzchni, a metody spawalnicze i pokrewne stanowią znaczny procent ich zastosowań.

Dr inż. Tomasz Chmielewski, dr hab. inż. Dariusz Golański - Politechnika Warszawska.
Remanufacturing ma szerokie znaczenie i jest złożonym procesem technologicznym służącym do kompleksowego odtworzenia właściwości użytkowych przedmiotów technicznych $z$ jednoczesnym formalnym potwierdzeniem przydatności użytkowej. Czasem może umożliwiać uzyskanie nawet lepszych właściwości eksploatacyjnych przedmiotu niż te sprzed procesu odtwarzania.

Stosowanie remanufacturingu powoduje m.in. oszczędność ok. $80 \%$ energii zużywanej na wyprodukowanie nowego przedmiotu.

\section{Charakterystyka remanufacturingu}

W ostatnich latach w literaturze technicznej remanufacturing jest dość popularnym tematem, jednak $z$ jego precyzyjnym zdefiniowaniem wciąż są kłopoty. $Z$ jednej strony jest to wynikiem trudności precyzyjnego tłumaczenia $z$ języka angielskiego, $z$ drugiej, funkcjonowania w nomenklaturze wielu bliskoznacznych terminów oraz elastyczności samego procesu pod względem stosowania i uzyskiwanych rezultatów. $Z$ remanufacturingiem kojarzą się takie słowa jak: reperacja, regeneracja, recykling, odnowa, naprawa itp. Każde $z$ tych określeń jest jego tłumaczeniem, ale żadne nie oddaje jego istoty. 


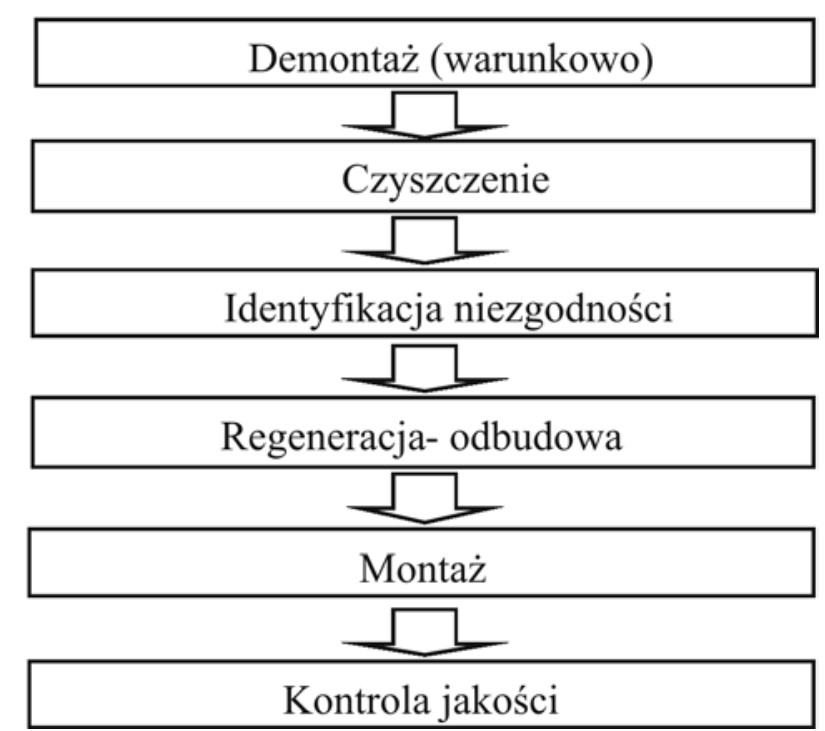

Rys. 1. Przebieg procesu remanufacturingu

Fig. 1. The scheme of remanufacturing process

Remanufacturing oznacza proces technologiczny przywrócenia eksploatowanego produktu do stanu co najmniej takiego, jaki zawiera specyfikacja oryginalnego produktu (z punktu widzenia klienta), oraz nadający temu produktowi formalną gwarancję, która jest co najmniej taka jak dla przedmiotu nominalnego [1].

Jest to proces technologiczny, dzięki któremu produkt przywracany jest ze stanu nieużyteczności do stanu o jakości co najmniej nominalnej. Najczęściej dotyczy przypadków zużycia części maszyn w sposób przewidywany na etapie projektowania oraz właściwy dla warunków eksploatacji, rzadziej dotyczy niespodziewanej awarii. Obecnie w wielu przypadkach projektowania drogich maszyn i ich części składowych uwzględnia się ich działanie w przyszłości, a nawet przygotowuje gotowe procedury. Im bardziej złożony i skomplikowany technicznie jest wyrób, tym więcej korzyści przynosi jego odnowa (koszty wytworzenia są wielokrotnie większe niż odnowa). Choć każdy przypadek odtworzenia części maszyn jest traktowany indywidualnie, można wyróżnić sześć głównych etapów procesu technologicznego (rys. 1).

W literaturze funkcjonuje wiele definicji remanufacturingu. W pierwszym opublikowanym raporcie na ten temat Lund opisuje go jako „... proces przemysłowy, $w$ którym zużyte produkty są przywracane do stanu użyteczności poprzez szereg procesów przemysłowych, począwszy od demontażu poprzez czyszczenie, naprawę i testowanie. Następnie elementy są ponownie montowane w maszynie z której zostały wymontowane. Remanufacturing prowadzi do uzyskania przez odtworzenie jednostki równoważnej, a czasem nawet o wyższej wydajności i trwałości w stosunku do pierwotnego nowego produktu" [2]. W tablicy I pokazano porównanie przebiegu klasycznej naprawy i remanufacturingu.

Metoda ta jest połączeniem 3R (reduce - redukcji; reuse - ponownego użycia; recycle - recyklingu).
Tablica I. Naprawa - remanufacturing, porównanie procesów i charakterystyki produktów [2]

Table I. Repair - remanufacturing, process comparison and product characterization

\begin{tabular}{|c|c|}
\hline Remanufacturing & Naprawa \\
\hline \multicolumn{2}{|c|}{ Proces } \\
\hline Produkt używany & produkt wadliwy \\
\hline Całkowity demontaż maszyny & wykrywanie uszkodzenia \\
\hline Czyszczenie części & demontaż wadliwych części \\
\hline $\begin{array}{l}\text { Regeneracja części lub uzu- } \\
\text { pełnienie przez nową część }\end{array}$ & $\begin{array}{l}\text { przywrócenie lub wymiana } \\
\text { uszkodzonej części }\end{array}$ \\
\hline Montaż części & montaż części \\
\hline Produkt zregenerowany & produkt zreperowany \\
\hline \multicolumn{2}{|c|}{ Właściwości } \\
\hline Proces przemysłowy & proces jednostkowy \\
\hline $\begin{array}{l}\text { Przywrócenie właściwości } \\
\text { nowego produktu }\end{array}$ & indywidualna naprawa \\
\hline $\begin{array}{l}\text { Klient otrzymuje własny } \\
\text { lub równoważny produkt }\end{array}$ & $\begin{array}{l}\text { klient otrzymuje } \\
\text { własny produkt }\end{array}$ \\
\hline $\begin{array}{l}\text { Produkt posiada gwarancję } \\
\text { użyteczności }\end{array}$ & $\begin{array}{l}\text { gwarancja pokrywa } \\
\text { tylko zakres reperacji }\end{array}$ \\
\hline $\begin{array}{l}\text { Zmodernizowany } \\
\text { do współczesnej technologii }\end{array}$ & $\begin{array}{l}\text { produkt utrzymuje } \\
\text { wcześniejszy standard }\end{array}$ \\
\hline
\end{tabular}

W XXI wieku nazwa ta nabiera coraz większego znaczenia.

W większości wiodących gospodarek światowych rola remanufacturingu jest postrzegana jako bardzo istotna. Podkreślił to prezydent Bush. który powiedział, że we współpracy z odpowiednimi organizacjami międzynarodowymi należy: zmniejszyć ilość odpadów, ponownie wykorzystywać zasoby i surowce oraz zmniejszyć bariery dla międzynarodowego przepływu towarów, materiałów i technologii recyklingu i remanufacturingu.

Potwierdzeniem zainteresowania remanufacturingiem liderów światowej gospodarki jest również powołanie do życia Narodowego Kluczowego Laboratorium Remanufacturingu (ang. National Key Laboratory of Remanufacturing) w Chinach w Pekinie, które pracuje na potrzeby wojska i przemysłu cywilnego.

\section{Ekonomiczne i środowiskowe uwarunkowania procesu}

Według Stowarzyszenia Automotive Parts Remanufacturers produkty odzyskiwane zachowują równoważność $400 \times 10^{9}$ BTU (1 BTU = $\left.1055 \mathrm{~J}\right)$ energii rocznie. Remanufacturing statystycznego produktu oszczędza ok. $80 \%$ energii, która zostałaby wykorzystana do produkcji nowej części, jest zatem narzędziem, które może posłużyć do zmniejszenia nadmiernej emisji gazów cieplarnianych. Każdy zużyty milion BTU energii emituje $140 \mathrm{~kg} \mathrm{CO}$. Tak więc oszczędność energii $400 \times 10^{9} \mathrm{BTU} / \mathrm{r}$. pozwala zmniejszyć emisję dwutlenku węgla $\mathrm{CO}_{2} \mathrm{O} 28000$ t rocznie. Remanufacturing stosowany szerzej niż obecnie w przemyśle mógłby wnieść istotne oszczędności energii i zmniejszyć znacząco emisję gazów cieplarnianych.

Emisja gazów cieplarnianych (GHGE - Green House Gas Emission) wynika z różnych działań podczas 


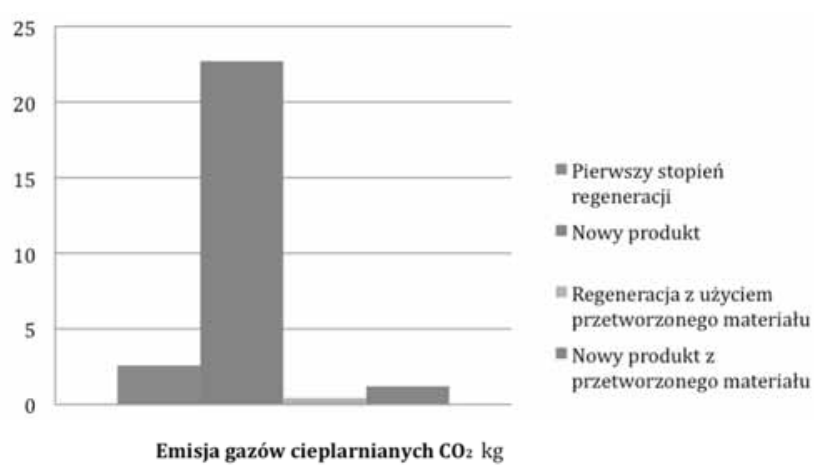

Rys. 2. Wielkość emisji gazów cieplarnianych [3]

Fig. 2. The emission of greenhouse gases $\{3\}$

produkcji materiału. Zawartość GHGE została ustalona jako iloczyn współczynnika emisji i masy materiału zużytego w nowej produkcji i regeneracji [3]. Obliczono ją dla następujących materiałów: stal $-1,08 \mathrm{~kg} \mathrm{CO}$, aluminium - $5,5 \mathrm{~kg} \mathrm{CO}_{2}$, żeliwo $1,08 \mathrm{~kg} \mathrm{CO}$, miedź $-7 \mathrm{~kg} \mathrm{CO}$, tworzywa sztuczne $-2,45 \mathrm{~kg} \mathrm{CO}_{2}$. Podane wskaźniki zostały obliczone na podstawie badań w USA oraz rynku energii, który różni się w innych krajach. Ilość GHGE wygenerowana podczas recyklingu typowego samochodu o masie $1150 \mathrm{~kg}$ to 147 $\mathrm{kg} \mathrm{CO}_{2}$. Na rysunku 2 przedstawiono wyniki emisji gazów cieplarnianych z 4 procesów: produkcji z nowych materiałów $-22,7 \mathrm{~kg} \mathrm{CO}_{2}$, remanufacturingu $-2,58 \mathrm{~kg}$ $\mathrm{CO}_{2}$, nowej produkcji $\mathrm{z}$ materiału wtórnego $-1,2 \mathrm{~kg}$ $\mathrm{CO}_{2}$ oraz regeneracji $\mathrm{z}$ użyciem surowców wtórnych $-0,43 \mathrm{~kg} \mathrm{CO}_{2}$.

Podczas realizacji procesu produkcyjnego powstaja odpady, których średnia masa wynosi $30 \%$ masy wyprodukowanych części. W przypadku remanufacturingu odpady stanowią znikomy procent masy produktu przywróconego do użytkowania.

Badania przeprowadzone przez Instytut Fraunhofera w Stuttgarcie wykazały, że w ujęciu globalnym rocznie energia zaoszczędzona dzięki procesowi remanufacturingu równa jest $w$ przybliżeniu energii wytworzonej przez pięć elektrowni jądrowych lub 10774000 baryłek ropy naftowej, która odpowiada flocie 233 tankowców [4].

Remanufacturing to ciągle rosnący rynek. Badania dowodzą, że firmy zaangażowane $w$ tym przemyśle wykazują znaczny wzrost i zyski nawet w czasach spowolnienia gospodarczego. Według raportu An American Resource w USA w branży remanufacturingu w 2003 r. 70000 firm zatrudniało 480000 pracowników i generowało roczne obroty na poziomie 53 mld dolarów [3].

Różnorodność produktów i osób korzystających $z$ tej branży jest ogromna. Zachowanie przemysłu i konsumentów potwierdza walory ekonomiczne i środowiskowe odtwarzania właściwości użytkowych przedmiotów technicznych, które wcześniej były złomowane. Nawet środowiska Zielonych wspierają koncepcję remanufacturingu.

\section{Uwarunkowania techniczne stosowania procesu}

Każda część, nawet zaprojektowana i wyprodukowana z najlepszego materiału, kiedyś ulegnie zużyciu.

Powierzchnie robocze najczęściej zużywają się w wyniku wzajemnego oddziaływania: procesów tarcia, obciążenia udarowego, podwyższonej i wysokiej temperatury oraz korozji.

Najprostszym wskaźnikiem zużycia jest ubytek masy materiału warstwy wierzchniej (roboczej), wynikający głównie z odkształcenia plastycznego, tarcia, korozji oraz pękania. $Z$ badań prowadzonych nad zużyciem części maszyn wynika, że ok. 50\% ulega zużyciu ściernemu, $15 \%$ adhezyjnemu, $8 \%$ - erozji, $8 \%$ - frettingowi, $5 \%$ - korozji, a $14 \%$ - łącznemu oddziaływaniu korozji, erozji i ścierania [5].

\section{Zastosowanie spawalnictwa w remanufacturingu}

Metody spawalnicze i pokrewne znajdują szerokie zastosowanie $w$ tym procesie, najczęściej $w$ takich przemysłach, jak: przemysł wydobywczy, przemysł petrochemiczny, transport szynowy, przetwórstwo tworzyw sztucznych, transport samochodowy, lotnictwo, budownictwo maszyn przemysłowych, energetyka, hutnictwo szkła.

W zasadzie wszystkie metody spawalnicze znajdują zastosowanie w remanufacturingu - od napawania elektrodą otuloną przez napawanie laserem, aż po metody natryskiwania cieplnego. Jako materiały powłokowe stosowane są wszystkie spawalne stopy metali, kompozyty metalowo-ceramiczne, ceramika i fazy międzymetaliczne oraz materiały powłokowe wytwarzane in situ [6]. W tablicy II przedstawiono stosowane w remanufacturingu metody spawalnicze na tle innych metod mechanicznych.

$\mathrm{Na}$ rysunkach przedstawiono przykłady napawania będącego pośrednim etapem odtworzenia właściwości użytkowych części maszyn. Na rysunku 3 i 4 pokazano widok zewnętrzny oraz mikrostrukturę napoiny wykonanej metodą napawania mikroplazmowego na powierzchni roboczej formy stosowanej w przetwórstwie tworzyw sztucznych. Rysunek 5 przedstawia widok podczas napawania i po obróbce mechanicznej napawanego metodą TIG łożyska ślizgowego prasy.

Przedstawione przykłady świadczą o dużej roli, jaką procesy spawalnicze odgrywają $w$ procesie odtwarzania zniszczonych czy zużytych powierzchni. Przy znacznie niższych kosztach procesy napawania czy natryskiwania zapewniają często kilkakrotnie dłuższą trwałość zmodyfikowanych części maszyn i narzędzi w porównaniu z nowymi wyrobami. Duża różnorodność spawalniczych metod regeneracji powierzchni zapewnia możliwość doboru właściwego procesu praktycznie niemal w każdym obszarze zastosowań remanufacturingu. 
Tablica II. Porównanie metod spawalniczych stosowanych w remanufacturingu z innymi metodami mechanicznymi Table II. Comparison of welding methods used In remanufacturing together with other mechanical methods

\begin{tabular}{|c|c|c|c|c|c|}
\hline \multicolumn{3}{|c|}{ Metody mechaniczne } & & \multicolumn{2}{|c|}{ Metody spawalnicze } \\
\hline \multicolumn{4}{|c|}{$\begin{array}{l}\text { Obróbka wymiarowa, tulejowanie, spęczanie, } \\
\text { wkładki regeneracyjne, prostowanie, obróbka nagniataniem }\end{array}$} & $\begin{array}{l}\text { Natryskiwanie } \\
\text { cieplne }\end{array}$ & Napawanie \\
\hline \multicolumn{2}{|l|}{ Metody statyczne } & \multicolumn{2}{|l|}{ metody dynamiczne } & \multirow{3}{*}{$\begin{array}{l}\text { gazowe, łukowe, } \\
\text { plazmowe, deto- } \\
\text { nacyjne, laserowe }\end{array}$} & \multirow{3}{*}{$\begin{array}{l}\text { łukowe: } \\
\text { MMA, GTA, GMA, SAW, } \\
\text { FCAW, MCAW, } \\
\text { plazmowe, laserowe, wiązka } \\
\text { elektronów }\end{array}$} \\
\hline Naporowo -toczne & ślizgowe & $\begin{array}{l}\text { nagniatanie } \\
\text { skoncentrowanym } \\
\text { źródłem energii }\end{array}$ & $\begin{array}{l}\text { nagniatanie } \\
\text { rozproszonym } \\
\text { źródłem energii }\end{array}$ & & \\
\hline $\begin{array}{l}\text { Krążkowanie } \\
\text { Rolkowanie } \\
\text { Kulkowanie }\end{array}$ & $\begin{array}{l}\text { przetłaczanie } \\
\text { diamentowanie }\end{array}$ & młotkowanie & śrutowanie & & \\
\hline
\end{tabular}

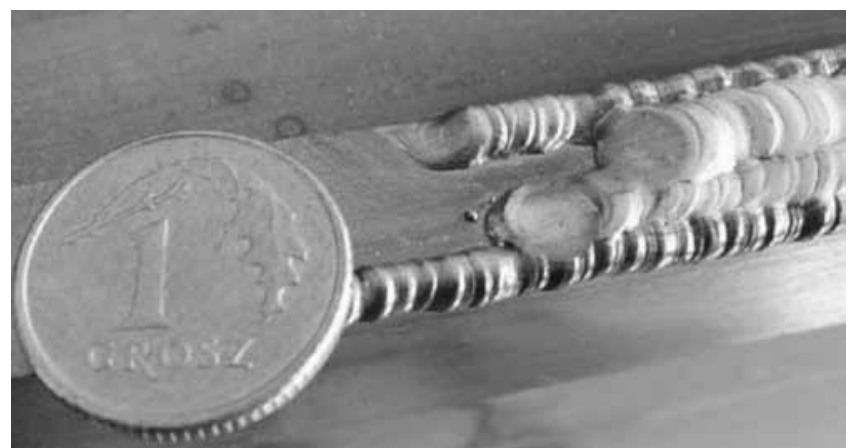

Rys. 3. Napoina mikroplazmowa wykonana na powierzchni roboczej formy stosowanej w przetwórstwie tworzyw sztucznych

Fig. 3. The picture of a microplasma hardface produced on the working surface of a mold used for plastics processing

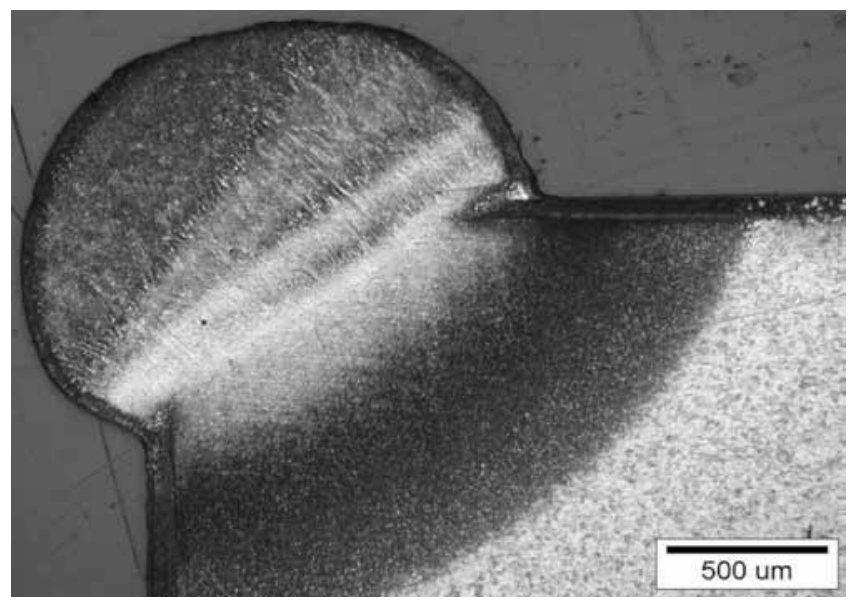

Rys. 4. Mikrostruktura napoiny mikroplazmowej wykonanej na powierzchni roboczej formy stosowanej w przetwórstwie tworzyw sztucznych

Fig. 4. The microstructure of a microplasma hardface produced on the working surface of a mold used for plastics processing

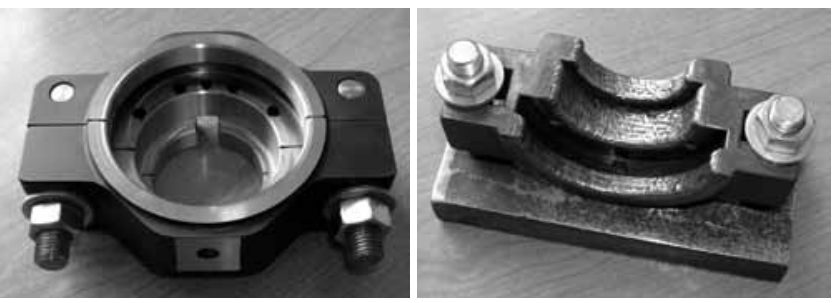

Rys. 5. Łożysko ślizgowe prasy na etapie napawania metodą TIG oraz po obrobieniu mechanicznym na wymiar nominalny

Fig. 5. The picture of a press plain bearing hardfaced by TIG and after mechanical treatment

\section{Podsumowanie}

Remanufacturing jako proces technologiczny ma w przemyśle szerokie i głęboko uzasadnione zastosowanie. Kluczowe dla tego procesu są spawalnicze i pokrewne metody wykonywania powłok o charakterze odtwórczym i modyfikacyjnym. Metody te są systematycznie rozwijane nie tylko pod kątem łączenia materiałów konstrukcyjnych, ale również w zakresie odtwarzania właściwości użytkowych części maszyn. Perspektywa rozwoju remanufacturingu w najbliższym czasie jest również sygnałem dla branży spawalniczej, otwierającym nowe rynki i stawiającym nowe wyzwania.

\section{Literatura}

[1] Winifred L. ljomah, Steve Childe, Chris McMahon: Remanufacturing: A Key Strategy for Sustainable Development. Department of Mechanical Engineering, University of Bath, Bath, United Kingdom. Department of Computer, Communication and Electronic Engineering, University of Plymouth, Plymouth, United Kingdom.

[2] Lund R, Hauser W.: Report: An American Resource. Boston Uniwersity; Boston, 2003.

[3] Kim H, Severengiz S, Skerlos S, Seliger G.: Economic and Environmental Assessment of Remanufacturing in the Automotive Industry. 15th CIRP International Conference on Life Cycle Engineering, 2008.

[4] Steinhilper R.: Remanufacturing The Ultimate Form of Recycling. Fraunhofer IRB Verlag, 1998.

[5] Madej E, Wrotkowski J.: Regeneracja części spawaniem i napawaniem. Wydawnictwa Naukowo-Techniczne; Warszawa, 1973.

[6] Chmielewski T., Golański D.: The new method of in-situ fabrication of protective coatings based on FeAl intermetallic compounds. Przyjęte do druku w Journal of Engineering Manufacture, 2011. 